\title{
Corrigendum: Interaction with the BRCA2 C terminus protects RAD51-DNA filaments from disassembly by BRC repeats
}

Owen R Davies \& Luca Pellegrini

Nat. Struct. Mol. Biol. 14, 475-483 (2007); published online 21 May 2007; corrected after print 5 June 2007

In the version of this article initially published, the abstract mistakenly included the phrase "RAD51-binding models." It should read

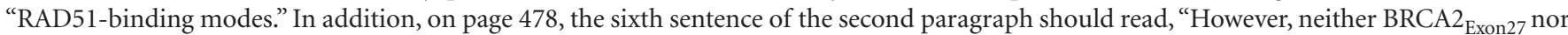
BRCA2 $2_{\text {Exon27-Ph }}$ interacted with the monomeric form of RAD51 (Fig. 4c), although BRCA2 Exon27 bound a GST-wild-type RAD51 fusion protein (Fig. 4d)." The errors have been corrected in the HTML and PDF versions of the article. Polymerase $\mu$

Andrea F Moon, Miguel Garcia-Diaz, Katarzyna Bebenek, Bryan J Davis, Xuejun Zhong, Dale A Ramsden, Thomas A Kunkel \& Lars C Pedersen

Nat. Struct. Mol. Biol. 14, 45-53 (2007); published online 10 December 2006; corrected after print 15 June 2007

In the version of this article initially published, the crystallization conditions were incorrectly reported. The correct conditions are as follows: $95 \mathrm{mM}$ sodium citrate ( $\mathrm{pH}$ 5.6), 19\% (v/v) isopropanol, 19\% (w/v) PEG 4,000 and 5\% (v/v) glycerol. The error has been corrected in the HTML and PDF versions of the article. The authors apologize for any inconvenience this may have caused. 